\title{
Revisión del constructo de Identidad en la Psicología Cultural
}

\section{Review of the construct the Identidy in the Cultural Psychology}

\author{
Sergio González R. ${ }^{1}$ \\ Héctor Cavieres H. ${ }^{2}$ \\ Carlos Díaz C. ${ }^{3}$ \\ Mariela Valdebenito S. ${ }^{4}$
}

\begin{abstract}
Resumen
El presente texto realiza una mirada actualizada sobre el constructo Identidad desde las perspectivas Historicista y Socioconstruccionista en Psicología Social y Cultural. Se analizan los contenidos determinantes de la constitución de la Identidad, tales como los propios de la individuación, de la organización de los significados, de los mediadores simbólicos de la experiencia, de la intersubjetividad y las posibles fronteras culturales de la Identidad.

Este trabajo es producto del intercambio académico realizado en el Seminario de Psicología Cultural del Programa de Doctorado en Psicología de la Universidad de Chile, impartido el primer semestre 2005 por el primer autor.
\end{abstract}

Palabras claves: Identidad, Modernidad, Individuación, Significado, Mediadores Simbó licos, Socioconstruccionismo.

\footnotetext{
Abstract

This study takes a fresh look at identity constructs as viewed from the perspective of the historicistic and socioconstructivist schools of thought within the field of social and cultural psychology. It analyses contents that exert a decisive influence over the formation of identity, such as the determinants of individuation, the organization of meaning, symbolic measurements of experiences, intersubjectivity and the possible cultural frontiers of identity.

The document is an outcome of the exchange of academic ideas and views that took place during the Seminar on Cultural Psychology offered by the first-named author as part of the University of Chile's doctoral programme in psychology in the first semester of 2005.

Key words: Identidy, Modernity, Individuation, Meaning, Symbolic Mediators, Socioconstruccionism.

${ }^{1}$ Psicólogo y Antropólogo. Doctor en Psicología. Académico Universidad de Santiago de Chile y Universidad de Chile.segonzal@usash.cl

2 Psicólogo. Universidad de Chile.

${ }^{3}$ Psicólogo. Académico Pontificia Universidad Católica.

${ }^{4}$ Psicóloga, Académica Universidad de Talca.
} 


\section{Psicología sociocultural en el contexto de la Psicología social.}

Para situar el constructo de identidad social en el marco de la psicología sociocultural resulta indispensable primero ubicarla en el marco general de la psicología, ello implica evidenciar su relación con la psicología social, y en particular con el socioconstruccionismo.

¿Y porqué con el socioconstruccionismo? porque puede plantearse que la psicología sociocultural corresponde a un área de estudio, a una perspectiva que pone su análisis en los fenómenos culturales desde un enfoque psicosocial, y que a nivel epistemológico se sostiene desde un marco socioconstrucionista. Lo que estamos señalando entonces es que lo que se conoce como Psicología Cultural más que un modelo epistemológico corresponde a una perspectiva, a un área de estudio. Cuya base es primordialmente socioconstructivista, pero no es esta su única base, de hecho hay quienes proponen que la psicología cultural se constituye en una suerte de tránsito desde la psicología social experimental hacia el socioconstruccionismo. Esto es que hay quienes proponen a la psicología cultural como un intento de unión entre la psicología social experimental y la postura social construccionista, tomando la epistemología del último pero dándole un énfasis a la construcción de conocimiento a partir de lo empírico, propio de la primera (Jost y Kruglansky, 2002)

El socioconstruccionismo de acuerdo a Ibáñez (1979) se basa en la comprensión de la realidad como construcción social, esto es entender que lo"real" surge como expresión de la actividad humana. Lo sociocultural por tanto analizará entonces los resultados, procesos de esta construcción social, extiéndase por ejemplo, elementos como la cultura, la política, las ideologías y, por supuesto, el lenguaje. Ello partiendo de la premisa de que estos procesos deben ser mirados tanto en su carácter global como local, o sea, siempre en contexto. Es importante, destacar, que la persona en definitiva no reacciona a la realidad "tal cual es" sino más bien a como la construye o interpreta (Ibáñez, 1979).

Un de las ideas mas potentes que pueden derivarse a partir de la lógica de la "construcción" es el hecho que la realidad no se presenta como una externalidad, como un afuera o como la variable independiente. $\mathrm{Si}$ la realidad se construye y, el individuo mismo, junto con sus ideas, identidad, valores, actitudes etc. son parte de esa realidad, ninguno de los dos es, entonces, definible con independencia del otro, luego la tradicional dicotomía entre individuo y sociedad carece de sentido.

Distinto de lo anterior resulta ser el modelo clásico de la psicología social experimental, que si entiende la existencia de una realidad externa y que mantiene las características de lo que desde la epistemología de las ciencias sociales se conoce como esquema analítico. Esto es, el monismo metodológico que dice relación con entender que el método de aproximación a los objetos es único y univoco: el método científico; otra característica, es el acento en la explicación causal, teniendo por objetivo lo que se describe como "interés dominador" que implica el control de naturaleza, de hacer los fenómenos susceptibles de control (Mardones, 1991).

Hasta aquí el socioconstruccionismo se plantea como un paradigma distinto a la psicología social, sin embargo, el primero surge como una reacción a este último y a partir de él, para llenar ciertos vacíos, por lo que al fin y al cabo, en la amalgama se constituye el campo de la Psicología Cultural, resultando más que posturas contrapuestas, en la práctica, perspectivas complementarias.

Históricamente se han suscitado polémicas en relación a la perspectiva socioconstruccionista, respecto de, por ejemplo, su status psicológico, o científico, sin 
embargo han habido también defensas señalando más bien que las diferencias con la psicología social experimental no son radicales sino que corresponden a énfasis con respecto a la relevancia de ciertos elementos o dinámicas, como por ejemplo el rol del lenguaje, de las significaciones o interpretaciones (Jost y Kruglansky, 2002).

Las vertientes socioculturales, socioconstruccionistas en psicología social han surgido como reacción a la psicología social experimental más radicalizada, que si bien ha tenido logros, éstos pueden enmarcarse más bien en la psicología individual pues remiten al análisis de procesos de orden cuasi biológico, lo social en esta psicología experimental se presenta como el "afuera", como un contexto, como un fondo, un escenario que induce cambios en las conductas de los sujetos (Ibáñez, 1979). Para ejemplificar este punto basta recordar los experimentos de Triplett sobre facilitación social, donde se observaban los cambios en el rendimiento de pedaleros, solos en una habitación vacía y luego en compañía de otros (Morales, 2003). En definitiva la psicología social experimental se centra más bien en los procesos por los cuales las personas llegan a pensar lo que piensan, de cosas, grupos, instituciones o de otras personas, porqué se incluyen o excluyen en determinadas interacciones o grupos sociales (Ibáñez, 1979).

El socioconstruccionismo, por otra parte, tiene por tema de estudio comprender los efectos del pensamiento y la cultura local en el pensamiento individual y colectivo, se pregunta por temas como la cultura, la política, y se asocia mucho más a la sociología (Jost y Kruglansky, 2002). Como ya es posible deducir, uno de estos énfasis distintivos de la perspectiva del socioconstruccionismo, respecto de la psicología social experimental, tiene que ver con la idea de significación de diferentes contextos, leyes, narrativas y fenómenos que al igual que en la psicología social experimental, son posibles de trabajar desde marcos experimentales, pero, buscando, eso si, evidenciar los procesos por los cuales la realidad se construye a través de actos, conversaciones, significaciones.

El énfasis de la psicología cultural, en relación al tema de la identidad, como ámbito más acotado de estudio, tendrá que ver con los procesos de significación, con las creencias, con lo idearios y como éstos se articulan en la identidad, en los proyectos de vida, en la conciencia de las personas. Cómo lo individual y lo social, que señalábamos como indisoluble, se articulan en un proyecto que es capaz de responder a elementos individuales que le hagan sentido al sujeto, pero que a su vez, tenga sentido en el marco más global donde ese sujeto se inserta.

La teoría de la identidad social (Tajfel,1984) tiene las características de vincular al sujeto con su contexto en el aspecto de construcción identitaria, además, en esta lógica de tránsito propuesta, esta teoría se constituye en un avance desde lo experimental, ya que teniendo su raigambre en ello se articula en una teoría sociocognitiva. Ibáñez, por ejemplo, señala que la teoría de la identidad social, si bien se reconoce como una teoría sociocognitiva correspondería a una lógica socioconstructivista, porque su planteamiento respecto de la génesis o la conformación del propio autoconcepto es a partir de una construcción social, ubicando, entonces, a la cultura, a lo social en el centro mismo del individuo, en la propia estructura de éste, no sólo como una externalidad sino también como una interioridad. Lo social estaría entonces tanto dentro como fuera, aseveraría, Moscovici (Ibáñez, 1979).

Ante este panorama para aproximarse de manera más completa al tema de la identidad hay que acercarse entonces al socioconstruccionismo, a la psicología cultural, pues esto implica entender a la cultura como sentido común, como un lugar donde se generan los contenidos intersubjetivos que se comparten en las comunidades que los interpretan, es allí donde se generan los marcos de referencia, las representaciones socia- 
les, y por tanto sólo desde allí será posible entender la identidad en contexto.

En la crisis de la psicología social de los años 60 la teoría de la identidad social aparece como la punta de lanza en el ataque al individualismo en psicología social, ya que como señalábamos esta teoría establece una relación inexcusable entre los individuos y los elementos del contexto, de la naturaleza, de las relaciones sociales, de los grupos o categorías sociales a las que se pertenece, así como de la propia estructura social (Ibáñez, 1979). La identidad, entonces, aún como construcción individual, es también indisolublemente social. Esto es particularmente patente si se piensa en términos de contenidos y en como estos se anclan en grupos sociales los que, a su vez, se constituyen en mediadores para hacer llegar esos elementos identitarios a los sujetos.

La identidad se nos presenta entonces como un constructo relacional, individual y colectivo, conformado por dicotomías y polaridades pero en ningún caso dicotómico o excluyente.

A modo de síntesis, podemos en este marco, entender la identidad al modo de Erikson, esto es, comprender que así como los roles organizan y describen las funciones, la identidad por su parte organiza los significados. A pesar del tiempo transcurrido, la idea de este autor sobre la identidad cobra particular vigencia al describirla como la articulación entre lo individual y lo social a través de una proyecto particular que lleva también en su centro la esencia de un proyecto colectivo (Erikson, 1968).

\section{La Teoría de la Identidad Social: el tránsito de la psicología social experimental al socioconstruccionismo.}

Ya se ha venido esbozando la idea de que la teoría de la identidad social desarrollada por Henry Tajfel (1984) bajo una revisión histórica puede entenderse como una teoría que si bien se enmarca en lo sociocognitivo tiene una lectura sociocultural.

La teoría de la identidad social en gruesas líneas plantea que el autoconcepto se conforma al menos en parte por la identificación con los grupos de pertenencia y de referencia. Esto ocurre a través de tres procesos, a saber: categorización, comparación e identificación.

La categorización opera como un proceso psicológico de ordenamiento del mundo en categorías, es decir conjuntos de objetos, personas acontecimientos (o algunos de sus atributos) en tanto son semejantes o equivalentes entre si respecto a la actuación, intenciones o las actitudes de un individuo (Ibáñez, 1979).

Del proceso anterior se obtienen categorías sociales entre la cuales surge la distinción endo - exogrupal, según sean grupos a los que el sujeto se adscribe o no, y por tanto se constituirán en los referentes para la articulación del autoconcepto. Los individuos realizan comparaciones entre las categorías generadas (endo, exo) buscando siempre un saldo positivo para las categorías endogrupales (Morales, 1996).

La teoría se presenta en esta parte como cognitivo motivacional, aspecto que como veremos cobra gran relevancia en otros desarrollos teóricos a partir de esta teoría. Es cognitivo por el proceso de categorización, de ordenamiento de estímulos y motivacional porque en el proceso de comparación se pone en juego la "necesidad" de mantención de una autoestima positiva del sujeto, lo que se constituiría en definitiva en el telos de su existencia.

El último elemento de la tríada que compone la teoría de la identidad social es precisamente la identificación que tiene que ver con los elementos afectivos, evaluativos, derivados de la adscripción a un determinado grupo o categoría social, y que en definitiva es el elemento que completa la identidad so- 
cial. Como se señalaba, el aspecto cognitivo motivacional de la teoría ha sido tomado en lo que es acaso una de las líneas más interesantes de desarrollo e investigación. De esta línea y dentro de lo que algunos autores distinguen como una psicología política, desde vertientes sociocognitivas, surge la teoría de justificación del sistema (Jost y Kruglanski, 2002).

La teoría de justificación del sistema toma en cuenta esta necesidad de autoestima positiva entendiéndola como una necesidad de “justificación" de las ideas y el accionar de los sujetos, esta necesidad de justificación tendría, o mejor dicho operaría en tres niveles (Jost y Banaji, 1994):

Nivel personal: implicaría la necesidad de justificación del propio Yo, aquí se enmarcarían dispositivos como por ejemplo los mecanismos de defensa, o los métodos de reducción de la disonancia cognitiva.

Nivel grupal: necesidad de justificar la conducta del grupo de pertenencia y referencia. Los estereotipos el prejuicio o la discriminación operarían en este nivel

Del sistema: corresponde a la necesidad de justificar el ordenamiento social en su conjunto. Ello implicaría, por ejemplo, darle un lugar a las desigualdades que existen en la sociedad, tiene que ver con legitimar ciertas prácticas que mantienen a algunos grupos en posiciones de desventaja en relación a otros, pero en el marco de un funcionamiento global y no sólo de una relación intergrupal.

Este último nivel según la teoría opera de manera implícita, a través de una "falsa conciencia", esto es de manera no consciente, implícita, resultando muy interesante el hecho de que en general opera contra los intereses del propio grupo (si se lee desde el lugar de los grupos marginados o en desventaja social en determinado ámbito), y por tanto ayuda a la perpetuación de ciertos posiciones ventajosas para algunos y desventajosas para otros (Jost y Banaji, 1994).
En temas de análisis como el que se propone desde este desarrollo teórico se puede apreciar el tránsito de lo experimental a lo socioconstruccionista, bajo el amparo de la óptica sociocultural, en el sentido que es un teoría cuyo nivel de análisis es político y se pregunta por el ordenamiento social, temas mucho más cercanos a la sociología que a la psicología propiamente tal, pero que son analizados desde una perspectiva psicológica o psicosocial.

Al hablar de la teoría de la justificación del sistema se está asumiendo que la interpretación de la realidad que hagan las personas repercutirá en el mundo, aunque sea por ejemplo manteniéndolo como está, perpetuando las diferencias entre grupos y en definitiva el statuo quo. Lo anterior de manera clara evidencia una perspectiva socioconstruccionista de la teoría.

Por otra parte, también, es posible apreciar elementos de la psicología experimental, especialmente en las formas de estudio, por ejemplo estudios de memoria implícita, o a través de los tintes biologicistas. Pues ante la existencia de un nivel que opera al contrario de los demás y contra el propio Yo surge la pregunta de ¿Porqué sería necesario este nivel que operaría en sentido contrario de los otros dos? Ante lo cual una primera explicación plausible daría cuenta de la necesidad de mantención a un nivel de especie, pues sólo bajo una análisis en este nivel es posible concebir que algunos sujetos, si hacemos la analogía con el mundo animal, se "sacrifiquen", pues ello se entiende solamente si ello implica la subsistencia de la "manada", en este caso, del ordenamiento social.

Estamos, entonces, frente a un tema con múltiples niveles de análisis y por tanto un tema propio de la psicología sociocultural, ello por su carácter multivariado, porque para entender la existencia de elementos de falsa conciencia, de justificación del sistema, es necesario analizar fenómenos histórico contextuales, ideológicos, de comprensión 
del mundo, entendido siempre que las maneras de figurarse, entender y significar el mundo tienen impacto en como la realidad se genera construye mantiene y perpetua.

\section{Individuación y mediadores simbólicos de la experiencia}

Desde la perspectiva del enfoque histórico-cultural e instrumental desarrollado por Vygotski, Leontiev y Luria, entre otros, es posible avanzar la idea que la identidad sería un constructo socio-cultural que integraría en una sola instancia sus dos facetas: el identificarse con otros y la continuidad del yo. Tal integración sería resultado de la internalización de lo social a través del lenguaje que en un sólo movimiento generaría estas doble característica de la identidad. La internalización de lo social daría lugar a la apropiación transformadora de la herencia cultural a través de la actividad de los individuos en el mundo (Wertsch, 1996), y consecuentemente a la individuación.

Este proceso de internalización, no obstante, no implica necesariamente una individuación tal como se puede concebir en lo que Giddens denomina modernidad tardía (1994), la que puede entenderse como un proceso de desarrollo tendiente a la creciente autonomía del individuo, el que estaría confrontado a la necesidad de realización de un proyecto de vida definido por él mismo. La individuación, tal como se expone aquí, considera que el proceso de apropiación de representaciones y prácticas por parte de los individuos es también el mecanismo que prevalece en las sociedades pre-modernas en las que los roles sociales poseen una estabilidad y fuerza configurativa extraordinariamente potentes. El distingo entre estos dos escenarios de construcción identitaria parece residir en el grado en que se actualizan las presiones en relación a los requerimientos de definición del sí mismo (lógica autonómica) o de conformidad social (lógica heteronómica), polos que en el ámbito de los estudios transculturales y en psicología cultural comparada se tienden a rotular como orientación individualista y colectivista respectivamente. La primera, como lo señalan por ejemplo Camilleri y Malewska-Peyre (1997), refieren a sociedades en las que la endoculturación "absorbe la socialización" y estarían "saturadas por reglas y regulaciones", las que "deben ser respetadas por todos los miembros de la comunidad que aspiren a ser respetados y alcanzar la esencia de lo que se entendería por humanidad" ( $p$. 45). Esta forma de construcción social sería particularmente identificable en sociedades de reducido tamaño y complejidad según lo indican estos autores. Contrastando con ello, Camilleri y Malewska-Peyre (1997), señalan que en las sociedades modernas la cultura cesaría de ser un sistema de integración total, como sería el caso en sociedades menos complejas, y se transformaría solamente en aquello que los individuos de los diversos subgrupos reconocerían como lo que tienen en común entre ellos a pesar de sus diferencias. La dificultad para cristalizar representaciones compartidas producto de los incesantes y rápidos cambios y fragmentaciones que conlleva la vida en las sociedades complejas estaría a la base del giro desde una construcción social basada en la herencia cultural (enculturación) hacia una basada en los procesos de socialización con los contemporáneos en escenarios constantemente redefinidos.

Volviendo al rol que juega el lenguaje en la internalización de lo social, es posible senalar como una derivación lógica de este proceso es que este no sólo definiría el carácter semiótico del proceso de individuación sino que también el de la propia identidad, instancia en la que el proceso de individuación se cristalizaría. Tal derivación permite plantear la idea, que al igual que el lenguaje juega un rol mediador entre los individuos y el mundo así como de los individuos en relación a sí mismos (Vygotski, 1934), organizando las percepciones y acciones (J. Bruner, 
1985), la identidad, en tanto instancia semiótica estabilizada del yo y de la pertenencia social, constituiría un mediador de estas mismas relaciones. Ambas herramientas, lenguaje e identidad, jugarían roles imbricados, pero distintivos en los procesos de mediación de la actividad. Mientras el lenguaje tendría por función principal la organización del pensamiento, la identidad tendría por función organizar los diversos significados que tienden a conformarse y a estabilizarse a lo largo de la vida de los individuos y las comunidades como producto de la internalización de la herencia cultural así como por efectos de la actividad orientada a propósitos que estos realizan en el transcurso de sus existencias.

Entender el proceso de configuración de la identidad así como sus modalidades de acción en el marco de su caracterización en tanto que mediador instrumental, permite acercarse de un modo constructivo a la amplia gama de desafíos que plantea el comportamiento humano, ya sea para efectos de definiciones e intervenciones en el plano de lo individual como en los planos meso y macro social, pues resitua la cuestión identitaria en su funcionalidad con respecto a la regulación de la actividad, sacándola de la condición de dimensión meta en la que el discurso ideológico de la modernidad ha tendido a posicionarla (Habermas, 1988).

Para los efectos de una mejor comprensión de lo que se ha expuesto en cuanto al carácter mediador de la identidad, es necesario considerar algunos atributos significativos que en general caracterizan a los artefactos mediadores. Una característica crítica de las herramientas mediadoras es que estas actúan simultáneamente en dos direcciones divergentes. Por una parte en tanto que "medio para", facilitando y/o potenciando la acción de los individuos y comunidades, permitiéndoles realizar y construir escenarios de vida impensables con el sólo recurso a sus atributos naturales. Mientras que por otra, juegan un rol de "inter-mediadoras" de la actividad, separando y/o delimitando la acción de los individuos, entre individuos y de las propias comunidades en relación a los objetos finales de su actividad. Esta característica inter-mediadora (o mediatizadora) actúa restringiendo las acciones y sus alcances a los parámetros que estas herramientas definen en función de sus características particulares (Díaz, 2005). Así, por ejemplo, particulares características identitarias tenderían a posibilitar preferentemente los juicios y comportamientos congruentes con ellas y, en contraste, inhibir aquellos que no lo son. En un sentido general es posible pensar que tal mediación tendería a operar a través de un proceso que no sólo deformaría funcionalmente la relación que individuos y comunidades establecen con la realidad, como podríamos aseverarlo con base a a una analogía con la idea de representación mental operatoria desarrollada por Ochanin (1968), sino que también favorecería la ilusión de una identidad desapegada de las condiciones de su constitución, despojada de su naturaleza de herramienta que permite canalizar y articular propósitos de acción y que en definitiva aparecería como fin en sí.

La doble condición que, como se ha señalado, caracteriza las herramientas mediadoras está sin duda a la base tanto de las potencialidades como de las dificultades que conlleva trabajar con y sobre la dimensión identitaria. Así, la identidad puede constituirse en una potente palanca de acción y transformación social e individual, pero a la vez erigirse como condicionante insoslayable de esta acción y transformaciones.

Otra característica de significativa relevancia de las herramientas mediadoras reside en su carácter histórico, vale decir que estas se constituyen y transforman en el transcurso del devenir humano. Para efectos de la identidad tal característica resulta evidente dada la impronta hereditaria que la marca desde sus orígenes (las generaciones 
previas heredan significados identitarios a las generaciones posteriores), al igual que por los reconocidos efectos constructivos que las distintas socializaciones y ciclos que los individuos y comunidades vivencian en el transcurso de sus existencias tienen sobre la conformación y transformación identitaria. Esta característica evolutiva obliga a observar la identidad no sólo como "lo que es" (sus características presentes), sino que sobre todo como "lo que ha llegado a ser" (Martin, 2002). Reconocer esta característica conlleva implicancias metodológicas mayores: por una parte plantea una exigencia de análisis histórico y procesual de la conformación identitaria y, por otra, abre el escenario para la realización de fértiles ejercicios hipotéticos en relación a sus posibles futuros desarrollos. Esto último resulta clave para generar marcos comprensivos y de acción que no sólo se limiten a asumir y / o paliar el estado de cosas que afectan o involucran las características identitarias de individuos y comunidades, sino que se proyecten en una perspectiva de gestión transformadora desde las identidades, cuestión clave tanto para aquellos que se desempeñan en el ámbito de la acción social o en el plano terapéutico.

\section{La Identidad como una organización de Significados}

Ubicarnos en la perspectiva expuesta en el punto anterior supone desarrollar un modelo que permita, aunque sea de modo sucinto, identificar los elementos y relaciones que participan de la instancia identitaria. Para estos efectos es necesario retomar el hilo conductor definido por la lógica subyacente al proceso de individuación.

Como se ha señalado, la herencia cultural internalizada es crítica en la conformación identitaria, fijando no sólo los parámetros y significados del "sentido común", sino que también marcando a fuego las propias referenciaciones individuales (por ejemplo, nombres y apellidos, nacionalidad, origen social, etc.).
Por su parte, la actividad humana, por su carácter distribuido en el tiempo y el espacio, marcada por la segmentación de roles (la división del trabajo y de géneros, entre otras), por las tramas de relaciones que establece entre individuos y comunidades, etc., no sólo es un factor de reelaboración y evolución de las identidades heredadas, sino que es, sin duda, una potente constructora de nuevos significados identitarios. Ambos afluentes enmarcarían la organización de significados que constituye la identidad. En ella se articularían los distintos significados referenciales del yo individual y del ser de las comunidades, los que se conformarían y estabilizaría a lo largo de la vida de estos.

En la actualidad diversos autores han intentado dar cuenta de la forma en que se constituyen y organizan los significados identitarios, y si bien se tiende a asumir mayoritariamente el fuerte nexo entre los significados personales y sociales de que contiene la identidad, es posible reconocer aún una significativamente presente deriva dicotómica . Así por ejemplo, Côté y Levine (2002) sostienen un modelo de diferenciación identitaria en tres niveles de actualización: a) una identidad social, que designaría la(s) posición(es) de los individuos en la estructura social; b) una identidad personal referida a las experiencias individuales concretas enracinadas en las interacciones y c) una identidad del ego que referiría al sentido subjetivo más fundamental de la continuidad de la personalidad. En el primer plano, la identidad estaría influenciada por factores culturales y roles sociales, mayormente definida en el marco de las relaciones secundarias y de las relaciones personales establecidas con base a rol. En el segundo, los individuos encontrarían un "acople" entre las prescripciones derivadas de sus identidades sociales y el carácter único e idiosincrático de sus historias de vida y se encontraría mayormente afectada por las relaciones primarias de los individuos. El tercero, estaría principamente afectado por factores intra psíquicos y disposiciones biológicas, aunque re- 
queriría de la confirmación que otorgaría la relación con otros en el plano de las relaciones secundarias. Este modelo, si bien presenta numerosas ventajas desde el punto de vista práctico, en especial por que facilita la distinción de los respectivos ámbitos disciplinares al interior de las ciencias sociales, sugiere a su vez distingos estructurales que disgregan el concepto de identidad al asimilar las instancias y factores que influencian la construcción identitaria con instancias identitarias distintivas.

En contraste y de modo general, parece posible postular que los significados identitaros se construirían y transmitirían a través de al menos 3 instancias genéricas sucesivas que se imbricarían en el transcurso de sus desarrollos:

- Primaria: a través de la familia y comunidades de origen

- Secundaria: a través de la educación institucionalizada

- Terciaria: a través del ejercicio de roles de producción y/o reproducción social (parentales, laborales, ciudadanos, entre otros.)

Las dos primeras con énfasis en la internalización de lo social y la tercera con énfasis en la actualización y proyección trascendente de la identidad. Estas instancias de construcción identitaria configurarían en el tiempo un sistema complejo y dinámico, en la que las instancias previas sostendrían y determinarían el desarrollo de las posteriores, y estas ultimas transformarían a las previas por efectos de una reelaboración expansiva de los elementos identitarios anteriores. A modo de analogía, este proceso ocurriría de modo similar a aquel que ocurre en el transcurso del aprendizaje de segundas lenguas: el aprendizaje de la nueva lengua se soporta y se ve a la vez facilitado y delimitado por el conocimiento de la lengua originaria. y en retorno, la incorporación de la nueva lengua permite sin duda iluminar con una nueva perspectiva la lengua originaria, acrecentando su comprensión a pesar de las eventuales perturbaciones que el manejo de la nueva lengua pueda acarrear en el dominio de la primera lengua.

En esta dinámica es que la identidad se construye simultáneamente en todos sus planos en cada una de las sucesivas instancias por la que transita su desarrollo, es posible deducir una relación organica y de naturaleza entre los niveles individuales (yo), societales (grupales y macro) y culturales (contenidos valóricos y prácticos) de la identidad. No obstante, tal articulación debe a su vez hacerse cargo de la coexistencia de diversos significados identitarios no necesariamente incluyentes, aunque no necesariamente contradictorios entre sí: por ejemplo, ser bombero y contador, ser padre y estudiante, ser latinoamericano y occidental, ser chileno, de orígen aymara y ejecutivo transnacional.

De este modo, la identidad albergaría diversos significados identitarios que requirían sino articularse, al menos ser gestionadas de modo de sostener tanto la congruencia identitaria al interior de las actividades y contextos específicos de acción, como la propia consistencia identitaria en el tiempo. ¿Cuáles serían los mecanismos que aseguren la congruencia y consistencia identitaria?

Para uno de los fundadores del pragmatismo norteamericano, W. James (1918), la personalidad cumpliría esta función de integración, jugando el rol de "administrador" de las funciones psíquicas. Desde una lógica convergente, A.N. Leontiev (1978), enfatiza que la construcción de la personalidad resulta del mismo proceso de la actividad humana en el que se constituye la conciencia, indicándolas a ambas como momentos internos de dicha actividad. Del mismo modo es posible reconocer en la misma saga una intima relación entre identidad y conciencia, generadas ambas a la par con 
la actividad orientada a fines y el lenguaje (Luria, 1976). De este modo también es posible entender la identidad como "momentos" de la compleja actividad social, ubicados tanto en el plano subjetivo como en el de la intersubjetividad.

Otra derivación lógica que es posible sostener si aceptamos carácter semiótico de la organización identitaria, sería que el proceso de articulación identitaria sucedería con base a las propias herramientas semióticas que participan de su configuración. Esto, especialmente a través del uso de giros connotativos (desplazamiento en los énfasis en la estructura de significados identitarios), y giros denotativos (procesos de adquisición y/o de abandono de significados identitarios), mediados lingüisticamente (yo, nosotros, ellos, antes era, aquí soy, hablo en mi calidad de...) en el contexto de la actividad orientada a fines, permitiendo la articulación y el tránsito entre los distintos niveles identitarios. Este mecanismo permite afirmar que si bien hemos homologado en alguna medida, lenguaje e identidad en tanto que herramientas mediadoras, sin duda el lenguaje sería la herramienta mediadora por esencia, y que sería a través de él que los otros mediadores psicológicos se constituirían y operarían (Luria, 1976).

\section{Las fronteras culturales de la Identidad: Modernidad y proyectos biográficos}

Uno de los contenidos esenciales de la modernidad es la individuación, la cual presupone en las personas como fin último la superación de la alienación social, aceptando una visión multidimensional de la persona, lo que implica reconocer intereses, motivaciones y expectativas múltiples en cuya realización y concreción se expresaría la individualidad del sujeto social. Este proceso está teñido de múltiples tensiones en que la acción instrumental de la modernización tiende a que los individuos se concentren (es- pecialicen) en aspectos específicos de la realidad y que sus vidas se articulen en torno a un número limitado de focos de interés. La racionalidad simbólica implicaría paradojalmente lo contrario, la aceptación y construcción de la vida cotidiana en base a las diferentes dimensiones que contendría el proyecto de vida de las personas. (Giddens, 1994; Habermas, 1999).

Uno de los rasgos distintivos de la modernidad consiste en el entrelazamiento de dos extremos paradojales que traducen una extensionalidad y la intencionalidad: las influencias universalizadoras asentadas en el predominio de la razón, y las disposiciones personales que ejemplifican el protagonismo renovado de la subjetividad. En las ciencias sociales ambas vertientes o polos de pensamiento producen una acumulación desde la cual se repiensan la identidad y la modernidad. Las ciencias sociales, por tanto, forman parte de esta reflexibilidad institucional, del cómo nuestras sociedades se piensan y se plantean una agenda comprensiva de la realidad personal, institucional y cultural de nuestros días.

Entre las consecuencias operativas de la reflexibilidad institucional se encuentra la profunda reorganización del tiempo y el espacio; en este sentido, encontramos amplios mecanismos de desenclave, es decir, mecanismos que liberan las relaciones sociales de su fijación a circunstancias locales específicas, recombinándolas a lo largo de grandes distancias espacio-temporales. De este modo se transforma el contenido y la naturaleza de la vida social cotidiana en la modernidad (Giddens,1994). Además, como un orden postradicional renueva la dicotomía seguridad-inseguridad, mediante la cual, a pesar de su razón de ser instrumental, el conocimiento racional no aporta el convencimiento de la certidumbre en reemplazo de la posible seguridad que ofrecían las tradiciones y costumbres. La duda metódica. Un rasgo circunscrito a la razón crítica moderna, penetra en la vida de cada día y llena de contenido existencial al 
mundo social contemporáneo. La modernidad institucionaliza el principio de la duda radical y recalca que todo conocimiento adopta la forma de hipótesis, de proposiciones que deben ser revisadas, e incluso desechadas, por la creación de un nuevo marco de conocimiento. Es así que se instauran las nociones de confianza y de riesgo sobre nuevos contenidos, o dicho de otra manera, se reproducen los contenidos del riesgo y de la pérdida de confianza sobre la base de la certidumbre y los consensos que la modernidad misma ha generado. Esto significa estar en presencia de una espiral en que riesgo y certidumbre, en que confianza y disrupción son posibilidades abiertas y alimentadas por la misma modernidad. La modernidad es en sí una cultura del riesgo, lo que implica mirar nuestra realidad de hoy desde una perspectiva histórica, mediante la cual no se trata de falsificar los hechos, diciendo que, épocas anteriores estuvieron ausentes de riesgo o tuvieron condiciones mejoradas de sociabilidad. Lo diferente en la modernidad es la continua tendencia a la colonización del riesgo, a su coadaptación, a su superación, perojustamente su domesticación no termina nunca de ocurrir, sino que, muy por el contrario, se generan y reproducen nuevas situaciones, nuevas alternativas, nuevas configuraciones que presuponen renovados elementos de incertidumbre. Junto a ello, y esto puede ser diferente a la tradición, es que se valora en el plano personal y colectivo la asunción de cuotas de riesgo bajo los apelativos de innovación, aceptación del cambio, flexibilidad cognoscitiva, calidad de vida, acceso a satisfactores y superación del pasado.

Si bien es cierto que la modernidad reduce el riesgo de conjunto en ciertas áreas y modos de vida, no obstante, introduce nuevos parámetros de riesgo desconocidos en gran medida, o incluso del todo, en épocas anteriores. En la modernidad tardía, la influencia de los acontecimientos distantes sobre sucesos próximos o de intimidad del yo, se ha convertido progresivamente en un lu- gar común. A esto ha coadyuvado la masificación de los medios de comunicación impresos y electrónicos en que se mediatizan los contenidos con los cuales se interpretan las diferentes realidades. El énfasis que aporta novedad sobre estas realidades tiene que ver con el nuevo papel que cumple de manera refleja la conformación de identidades del yo o, dicho de manera más integral, los procesos de individuación y de subjetivación necesarios para aprender los contenidos mediáticos.

Entendiendo que el proyecto básico del yo, en conformación de la identidad, consiste en dar continuidad y verosimilitud subjetiva y colectiva a la crónica biográfica, la noción de estilos de vida adquiere una marcada preponderancia. La instauración de los estilos de vida aparece inscrita en la matriz dialéctica entre lo global y lo local, los que adquieren un marcado predominio en la transformación de la intimidad. Esta transformación, a su vez, está determinada por la nueva relación entre lo público y lo privado, en que lo público se privatiza, se subjetiviza $\mathrm{y}$ tiende a desaparecer su importancia expresada en contenidos abstractos y generalizables.

Otra línea de interpretación, en clave de frontera cultural de la identidad, tiene que ver con el secuestro de la experiencia; es así que los sistemas de adjudicación de significados pasan a constituirse en torno a comunidades de expertos, y son los criterios externos, es decir, los que dicta la modernidad, aquellos que alcanzan un mayor nivel de plusvalía social para interpretar lo que sucede en la vida privada y en la intimidad.

En esta misma línea encontramos la reflexión sobre la insignificancia personal, sentimiento que alude a la pérdida de sentido de la vida al no tener nada valioso que ofrecer. Esto se ha convertido en un problema psicológico característico en las coordenadas de la modernidad tardía, que conlleva a un aislamiento existencial que no sólo puede im- 
plicar situaciones de soledad (social), sino obstáculos para alcanzar los recursos morales necesarios para vivir una existencia plena y satisfactoria. Aquí es donde la autenticidad, una crítica de la autenticidad, se convierte en un valor eminente para entregar un marco de realización del yo, aunque como experiencia este proceso esté moralmente atrofiado. Podríamos decir que la modernidad en este sentido ha ofertado el desarrollo de las fuerzas expansivas del yo, lo que se ha llamado una política de la emancipación, pero su paradoja es inmediata, al estar vedados los medios y las condiciones para cumplir con su proyecto utópico abierto a todas las identidades personales y colectivas. La modernidad desde su matriz racionalista cree y reproduce diferencias, exclusión y marginación, o como señala Giddens, "las instituciones modernas al tiempo que ofrecen posibilidades de emancipación, crean mecanismos de supresión más bien que de realización del yo" (op cit, pp.14-15). No obstante, este autor es optimista, y amparado en los nuevos movimientos sociales, al igual que Touraine, plantea en base al compromiso, es decir, a una cultura del compromiso, una política de la vida interesada en la realización humana del yo, tanto en lo individual como en lo colectivo. Esta política de la vida es hereditaria del proyecto característico de la modernidad de una política de la emancipación. Este proyecto ha sido la matriz simbólica de toda la ilustración progresista y se convierte en la condición esencial para un programa comprensivo de las paradojas de la identidad en las coordenadas actuales.

\subsection{La trayectoria del yo en la Modernidad}

La identidad del yo es un invento de la modernidad, o por lo menos su búsqueda es un problema moderno, en que tal vez sus orígenes están en el individualismo occidental. Los contenidos adquiridos que son constitutivos del yo, marcarían una diferencia antagónica con las adscripciones colectivas determinadas por la cultura en las sociedades premodernas. Para Durkheim (1984), el individuo no existe en las culturas tradicionales y su presencia se constituye con la aparición de las sociedades modernas, y más en concreto, con la diferenciación que aporta la división del trabajo. En este sentido, el individuo surge como un reflejo de procesos sociales que contienen un alto nivel de complejidad.

Independientemente de lo discutible que puede ser el fondo de esta afirmación, -para Giddens lo es-, la preocupación por la identidad del yo es una temática que se instaura en la modernidad. En línea analítica se pueden distinguir los siguientes aspectos en la discusión:

a) El yo está visto como un proyecto reflejo del que es responsable el individuo. No somos lo que somos, sino lo que nos hacemos.

b) El yo realiza una trayectoria de desarrollo desde el pasado a un futuro previsto. Esta trayectoria del yo se constituye en una continuidad en que el individuo indaga sobre su pasado y prevé su futuro. Aquí hay una suposición de búsqueda de la coherencia derivada de la conciencia cognitiva de las diferentes etapas de la vida.

c) La reflexibilidad del yo es continua y generalizada en intervalos de tiempo regulares y, a veces, a cada momento se le pide al individuo que reflexiones sobre sí mismo acerca de lo que le sucede.

d) La identidad del yo presupone, como fenómeno coherente, una crónica explícita del yo. En esta crónica se busca la integración de los diversos contenidos de la historia biográfica. Esto presupone una interpretación que implica una elaboración que exige obviamente recursos creativos.

e) La realización del yo implica el control del tiempo. Esto significa mantener un diálogo con el tiempo como base de autorrealización, fundamentalmente en el 
establecimiento de zonas de tiempo personal por sobre los tiempos instrumentales.

f) La reflexibilidad del yo se extiende al cuerpo, como parte de un sistema de acción más que como un mero objeto pasivo. La conciencia del cuerpo es fundamental para captar la plenitud del momento e implica la capacidad de control de sí mismo y del entorno.

g) La realización del yo como equilibrio entre oportunidad y riesgo. La posibilidad de desprenderse de hábitos emocionales opresivos genera oportunidades para el desarrollo propio, donde se crean compromisos experenciales que permiten asumir una conciencia secular del riesgo, la cual es inherente a las estrategias del cálculo en el dimensionamiento del futuro.

h) La línea moral de realización del yo es una línea de autenticidad (ser fiel a uno mismo). La ética de la autenticidad elude los criterios universales. Ser sincero con uno mismo significa asumir un proceso activo de construcción del yo en que lo básico debe estar en liberarse de las dependencias y lograr la plenitud.

i) El proceso de la vida se contempla como un conjunto de pasajes. El individuo pasará con seguridad por ellos, sin estar institucionalizados ni acompañados de ritos formales. Todos ellos implican una pérdida y tal vez una ganancia, comprendiendo en cada caso un período de duelo para que la realización del yo siga su curso normal. Los pasajes de la vida dan contenido a la interacción entre riesgo y oportunidad. Resolver una transición importante en la vida significa someterse de manera consciente a riesgos interesantes a fin de plasmar las nuevas oportunidades a las que nos dan acceso las crisis personales.

j) La línea de desarrollo del yo es internamente referencial. La integridad personal, como logro de un yo auténtico, surge de integrar las experiencias de vida en la crónica del desarrollo del yo, en la creación de un sistema de creencias personales ante las cuales el individuo reconoce que ante todo se debe lealmente a símismo. Estos puntos de referencia se establecen desde dentro, en función de cómo el individuo construye/reconstruye la historia de su vida (Giddens, 1994: 99-104).

\subsection{Estilos y planes de vida.}

Aquí el telón de fondo se constituye en el sentido existencial de la vida configurado por la modernidad tardía. En el plano del yo, la actividad diaria se rige por el principio de la elección. La modernidad sitúa a la persona frente a una trama diversa de opciones, sin contar con información adicional y de contexto. Entre las consecuencias de esta situación encontramos la primacía del estilo de vida que como matriz es inevitable para el individuo. Esta noción inunda la producción de la modernidad tardía, ya que todas las personas se atienen a estilos de vida, no hay otra elección.

Un estilo de vida puede definirse como un conjunto de prácticas relativamente integradas que un individuo adopta no sólo porque satisfacen necesidades utilitarias, sino porque dan forma material a una crónica concreta de la identidad del yo. En los estilos de vida hay prácticas hechas rutinas, como las rutinas del comer, del vestir, las cuales están abiertas al cambio en concordancia con la naturaleza móvil de la identidad del yo. Cada una de las pequeñas decisiones que toma la persona durante el día, como, por ejemplo, qué ponerse, qué comer, cómo comportarse en el trabajo, con quién verse al finalizar la tarde, contribuye a estas rutinas. Esta opciones, además de otras de mayor amplitud y consecuencia, son decisiones referentes no sólo a cómo actuar sino a quién ser.

Equivocadamente se ha asimilado la noción de estilo de vida al área del consumo, pero también es necesario comprender lo que 
ocurre en el trabajo. El trabajo condiciona fuertemente las oportunidades de vida, el que debe entenderse en función de la accesibilidad a posibles estilos de vida. Bordieu (1988) destaca las variaciones de estilo de vida entre grupos como atributos de estratificación elementalmente estructurantes y no sólo como el resultado de las diferencias de clase en el reino de la producción. Por otra parte, la selección se ve influenciada tanto por presiones de grupo y por la visibilidad de los modelos de rol, como por las circunstancias socioeconómicas.

La pluralidad de elecciones es una característica de las sociedades postradicionales. Actuar en un mundo de acciones plurales y comprometerse en él es optar entre alternativas, ya que las marcas dejadas por la tradición están ahora en blanco. Por su parte, Berger (1974) denomina como pluralización de los mundos de vida a la expresión de complejidad, de diversidad y segmentación que ocurre tanto en los contenidos sociales como culturales. Un elemento particular de la segmentación es la diferenciación entre ámbitos público y privado, estando cada uno de ellos sujeto también a una pluralización interna. Las opciones de estilos de vida, de este modo, son decisiones que se ven caracterizadas por los medios de acción que se vehiculizan, siendo absorbidas por estos medios a expensas de otras alternativas posibles.

Se distinguen en la vida de un individuo, diferentes sectores de estilos de vida que refieren una parte de las actividades generales del individuo, el cual se adopta y lleva a cabo un conjunto razonablemente consistente de prácticas. Los sectores de estilo de vida son aspectos de la regionalización de las actividades. Estos sectores o territorios regionales del estilo de vida implican algún grado o nivel de diferenciación experencial y estructural.

Otro factor que condiciona la pluralidad de elección es el impacto existencial provocado por la naturaleza contextual de las creencias acreditadas. Es evidente el predominio de la experiencia mediatizada por los medios de comunicación en la elección de los estilos de vida. En ellos se encuentran contenidos e información pertinente sobre una amplia oferta de virtuales estilos de vida. El efecto collage de la televisión y la prensa da forma específica a la yuxtaposición de ambientes y elecciones potenciales de estilos de vida.

En este mar de opciones alternativas de estilos de vida el planeamiento en base a una(s) estrategia(s) de la vida adquiere una especial importancia. Los planes de vida son el contenido sustancial de la trayectoria proyectadamente organizada del yo. La planificación de la vida a través de acciones futuras es el intento de construir un relato o narrativa biográfica del yo. De igual modo, se distinguen los calendarios de plan de vida (Giddens,1994), en relación con los cuales se gestiona el tiempo personal de la vida. Esta cronología personalizada contiene los acontecimientos significativos de la biografía de cada individuo. La planificación de la vida personal no sólo depende de la preparación para el futuro, sino que además implica una reelaboración de los sucesos del pasado. A través de esta resignificación del pasado se prepara y construye el presente y el futuro, buscando establecer la línea de continuidad de la biografía como un todo. La planificación de la vida es un aspecto central de un fenómeno más inclusivo, el de la colonización del futuro.

\section{En línea de conclusiones: La (Re)construcción de Identidad}

La identidad es la fuente de sentido y de interpretación de la experiencia de las personas. La identidad del yo siempre es social (Erickson,1972). Se establece a través de la observación de sí mismo con los ojos de la mirada social que nos retroalimenta, o a partir de la imagen que de nosotros mismos nos devuelven los demás. Por tanto, en la interacción social, la alteridad moldea de acuerdo con sus respuestas los contenidos del 
self de cada persona en un proceso de construcción en espejo de la identidad.

Basándonos en las diversas aportaciones que hemos recogido en este texto podemos esquematizar el constructo de Identidad considerando los siguientes supuestos básicos:

La identidad es una construcción intersubjetiva, que se obtiene a través de la interacción social y en base a contenidos aportados por un otro relevante. Está contextualizada, mostrándose determinada en su fenomenología por las diferentes situaciones en que se manifiesta. La identidad es un texto en contexto: Una construcción diacrónica que se sitúa fenomenológicamente en una expresión contingencial.

La identidad es negociada -individual y colectivamente- a través de procesos de intercambio simbólico y de ajustes sucesivos entre actores, los que constituyen la construcción de intersubjetividad. Por tanto, la identidad es un producto, es decir, una construcción realizada en la interacción social desde los significados sociales disponibles. De igual modo, es un collage, en la modernidad no se puede pensar en identidades unidimensionales y univivenciales. La identidad, en este sentido, es múltiple y puede contener desarrollos paradojales y superpuestos.

Las identidades tienden a constituirse en conductas. De esta forma se confirman en sí mismas y explican el comportamiento social. Por tanto, la identidad es un espacio abierto en permanente construcción y reconstrucción en el proceso de individuación y deben distinguirse del desempeño de roles, ya que las identidades organizan el significado, mientras que los roles organizan las funciones. Estos se definen por normas dependientes de las instituciones y las organizaciones de la sociedad. Su peso relativo depende, para influir en la conducta de la gente, de las negociaciones y acuerdos entre los individuos y esas instituciones y organizaciones. Las identidades en el campo simbólico están determinadas por el proceso de individuación, que debe leerse como un proceso mayor en que las personas se instauran en la vida social.

En términos semejantes y desde una posición innovadora, Giddens, al referirse a la identidad en la modernidad tardía, período que caracterizaría al mundo occidental, señala que "la identidad propia no es un rasgo distintivo que posee el individuo. Es el yo entendido reflexivamente por la persona en virtud de su biografía" (Giddens, 1994:53). Para este autor, en el contexto del orden postradicional, el yo se convierte en un proyecto reflexivo: "cuanto más pierden su dominio las tradiciones y la vida diaria se reconstituye en virtud de la interacción dialéctica de lo global y lo local, más se ven forzados los individuos a negociar su elección de tipo de vida entre una diversidad de opciones. La planificación de la vida organizada de forma reflexiva se convierte en el rasgo central de la estructuración de la identidad propia" (op cit, p33). De este modo, las identidades se constituyen en torno a una racionalidad simbólica en que los proyectos de vida se construyen y se ordenan a partir de los estilos de vida que la modernidad pone a disposición de los individuos y la sociedad.

\section{Referencias Bibliográficas}

Berger P. (1974). The homeless mind. Harmondsworth. Penguin.

Bourdieu, P. (1988). La distinción. Madrid: Editorial Taurus.

BRUNER J. (1985). Vygotski: a historical and conceptual perspective in Wertsch, J. (Ed.) Culture and Cognition, vygotskian perspectives. Cambridge: Cambridge University Press

Camilleri, C. \& Malewska-Peyre, H. (1997). Socialitation and identity strategies in 
Berry, J.; Dasen, P. \& Saraswathi, T. (Ed.), Handbook of cross-cultural psychology, Vol 2, Boston: Allyn and Bacon

Cole, M. \& Engeström, Y. (1993). A culturalhistorical approach to distibuted cognition in Salomon, G. (Ed.) Distributed cognitions: psychological and educational considerations, Cambridge: Cambridge University Press.

Côté, J. \& Levine, Ch. (2002). Identity formation, agency and culture: a social psychological synthesis. NJ: Lawrence Erbaulm Associates.

DíAz, C. (2005). Transferring technologies to developing countries: a cognitive and cultural approach in Sternberg, R. And Preiss, D. (Ed.), Intelligence and technology: the impact of tools on the nature and development of human abilities, N.J: Lawrence Erbaulm Associates.

DurkheIM, E. (1984). The División of Labour in Society. London: Macmillan.

ERIKSON, E. (1968). Identity, youth and crisis. NY: Norton

ERICKSON, F. \& SchulTz, J. (1997). When is a context?, some issues in the analysis of social competence in Cole, M., Engeström, Y. \& Vasquez, O. (Eds.), Mind, Culture and Activity, Cambridge: Cambridge University Press.

GidDens, A. (1994). Modernidad e identidad del yo, Barcelona. Península.

Giddens, A. (1995) La Constitución de la Sociedad. Bases para la teoría de la estructuración. Buenos Aires: Amorrortu Editores.

Giddens,A. (1999). Consecuencias de la Modernidad. Madrid: Alianza Editorial.

GonZÁLEZ, S. (2003). Representación social de la Ciudadanía en jóvenes de enseñanza media y enseñanza universitaria: un análisis de estudios comparados en la ciuda- danía que viene. En: Arrau,A. (Ed.), Bases para la competencia en Chile. Santiago: Predes. Univ. de Chile. Ril Editores. pps. 139-177.

GonzÁlez, S. (1998). Modernidad, Ciudadanía y Etica: Relaciones Lógicas. En: Oikos. Universidad Católica Blas Cañas. Santiago de Chile. Año 2. $\mathrm{N}^{\mathrm{o}} 6$.

HABERMAs, J. (1988). Le discours philosophique de la modernité. París: Ed. Gallimard

Habermas, J. (1999). La Inclusión del Otro. Estudios de Teoría Política. Barcelona: Ed. Paidós.

IBAÑEZ, T (1979). Factores sociales de la percepción. Hacia una psicosociología del significado. Barcelona. Quaderns de psicologia, $\mathrm{N}^{\circ} 1$.

JAMES, W. (1918). The principles of psychology, NY: Dover

JosT \& BANAJI (1994). The role of sterotyping in sytem justificaction and the production of false consciousness. London. British Journal of Social Psychology.N 33.

Jost,J. \& Kruglanski,A. (2002). The estrangement of social constructionism and experimental social Psychology: history of the rift and prospects for reconciliation. Personality and social psychology rewiew, Vol 6, $\mathrm{N}^{\circ} 3$.

Jost, SidAnius (2003). Political Psychology, keys readings in social psychology. New York: Ed. Psychology Press.

Leontiev, A.N. (1978). Activity, conscienciousness and personality. Englewood Cliffs, NJ: Prentice-Hall

LePLAT, J (2001). La gestion des communications par le contexte. Revue électronique Pistes, Vol 3, n1

Luria, A. (1976). Cognitive development its cultural and social foundations. Harvard: Harvard University Press 
Mardones, J (1991). Filosofía de las ciencias humanas, materiales para una fundamentación científica. Barcelona: Ed. Antrophos.

Martin, J. (2002). Organizational culture. Thousands Oaks: Sage Publications.

Morales, J (1996). Identidad Social. Madrid: Ed. Promolibro.

Moscovici, S (1998). Psicología Social. Barcelona: Ed. Paidós.

Nisbett, R \& Masuda, T. (2003). Culture and point of view, Proceedings of the National Academy of Science of America, v100, n19, USA

Ochanin, D.A. (1968). Les hommes dans les systems automatisées. París: Dunod

SIEGAL, M. (1996). A clash of conversational worlds: interpreting cognitive development through communication in Resnick, L,; Levine, B. \& Teasley, S. (Eds.) Perspectives on socially shared cognition. Washington D.C.: APA

SteTSENKo, A. (2005). Activity as object-related: resolving the dichotomy of individual and collective planes of activity. Mind, Culture and Activity, Vol. 72 No 1, p. 70-88

TAJFEL,H (1984). Grupos humanos y categorías sociales. Barcelona : Ed. Heder. Vygotski, L. (1934/1997). Pensée et langage. París: La Dispute

WERTSCH, J. (1998). Mind in action. NY: Oxford University Press

Fecha Recepción Artículo: 15 de diciembre 2005 Fecha Evaluación Final: 10 de abril 2006 
